\title{
Physical and Chemical Evaluation of Tomato and Its Value Addition
}

\author{
Archana Kumari* and Jitendra Singh
}

Krishi Vigyan Kendra, Kasturbagram, Indore, India

*Corresponding author

\begin{tabular}{|l|}
\hline Ke y w o r d s \\
BOD, COD, $\mathrm{pH}$, \\
Halogens, Toxic \\
metals, etc.
\end{tabular}

A B S T R A C T

Tomato though botanically a fruit is generally considered as vegetable because of the way in which it is consumed. Fresh tomatoes are very refreshing and appetizing but cannot be stored for a long period. During peak season, about $25 \%$ of the produce is spoiled due to mishandling and such losses can be avoided by converting tomatoes into different value added products. Tomato can be processed into pulp, paste, puree, juice, ketchup and sauce. In India, tomato sauce and ketchup are very popular. The demand for tomato processing usually arises from a need to preserve the product for cooking purposes (inclusion in stews, soups, curries etc.) out of season or to add value for extra income. Traditionally, the most important methods used are concentration (to a paste or puree) and drying either fruit pieces or to a powder. Tomato as well other vegetable waste is generally characterized for various physical, chemical, or biological properties. Physical characterization of tomato wastes include estimation of weight, volume, moisture, ash, total solid, volatile solid (VS), colour, odour, temperature, etc., while Chemical studies include the measurement of cellulose, hemicellulose, starch, reducing sugars, protein, total organic carbon, phosphorus, nitrogen, $\mathrm{BOD}, \mathrm{COD}, \mathrm{pH}$, halogens, toxic metals, etc.

\section{Introduction}

Tomato is grown in India in abundance both in summer and winters. Tomato though botanically a fruit is generally considered as vegetable because of the way in which it is consumed.

Fresh tomatoes are very refreshing and appetizing but cannot be stored for a long period. During peak season, about $25 \%$ of the produce is spoiled due to mishandling and such losses can be avoided by converting tomatoes into different value added products. Tomato can be processed into pulp, paste, puree, juice, ketchup and sauce. In India, tomato sauce and ketchup are very popular. High quality products can be prepared from tomatoes by:

Using uniformly ripened, red coloured tomatoes.

Avoid prolonged heating and cool the product immediately after cooking.

Avoid using iron and copper equipments and utensils at any stage of processing.

The demand for tomato processing usually arises from a need to preserve the product for cooking purposes (inclusion in stews, soups, 
curries etc.) out of season or to add value for extra income. Traditionally, the most important methods used are concentration (to a paste or puree) and drying either fruit pieces or to a powder.

\section{Tomato and tomato products}

Fresh tomatoes are highly refreshing and appetizing. They are rich source of vitamins particularly vitamin $\mathrm{C}$. Commercial products from tomatoes include juice, puree, paste, ketchup, soup canned and dehydrated tomatoes. As a semi-finished product, tomato puree is prepared on a small scale while at large scale tomato paste has gained commercial significance. Both puree and paste are used for preparation of different finished products like ketchup, juice, soup etc. The method for preparation of different tomato products are discussed as under:

\section{Tomato juice/pulp}

Plant ripened and fully red tomatoes are used for juice making. All green, blemished and overripe fruits should be removed. The yields, colour and flavour of the juice depend on the degree of ripeness of the tomatoes and the variety. Tomatoes are washed thoroughly with water. They are crushed by means of fluted wooden roller-crushers. Tomato juice is either hot pulped or cold pulped. It is also extracted through screw type juice extractor. The juice is mixed with 0.4 to $0.6 \%$ salts to counteract the astringent taste of the juice. Sometimes, sugar is also added to improve the taste. The juice is packed in glass bottles or cans. Tomato juice is the unconcentrated product consisting of the liquid with a substantial portion of the pulp, expressed from ripe tomatoes with or without the application of heat and addition of salt. Tomato pulp/juice is the basic ingredient for preparation of different tomato products such as tomato puree, paste, ketchup etc.

\section{Method for preparation of tomato juice}

\section{Washing}

Tomatoes should be washed in plenty of running water to remove dust, dirt etc. present in cracks, wrinkles, folds and stem cavities not easily dislodged by gentle washing (Fig. 1).

\section{Crushing}

Tomatoes, after trimming are cut into four to six pieces for extraction of pulp. Alternatively, they may be crushed by means of fluted roller crushers or by passing through the fruit grater (Fig. 2).

\section{Pulping}

Tomato pulp can be extracted either by passing through the pulper after crushing without heating (cold pulping) or after boiling the crushed or whole tomatoes till softening followed by extraction of pulp in a pulper (hot pulping). During pulping, the fine juice and pulp passing through the sieves of pulper are collected while skin and seeds are separated through another end.

\section{Cold pulping}

It is commonly referred to as cold break process in which the tomatoes after washing are sliced or crushed in a fruit grater and immediately passed through a pulper to extract the pulp.

\section{Hot pulping}

It is also known as hot break process.

The tomatoes after slicing or crushing in a fruit grater are boiled in pressure cooker/steam jacketed stainless steel kettle or aluminium pans till softening to facilitate pulp extraction in pulper. Softened tomatoes passing through pulper is shown in Figure 3. 


\section{Equipment for juice/pulp extraction}

Tomato juice/pulp is extracted either by passing the crushed tomatoes through a continuous spiral press or pulper.

\section{Continuous spiral press}

It consists of a long spiral screw which presses the tomatoes against a tapered screen of fine mesh. The juice passes through the screen while seeds and peel are removed from the lower end of the sieve.

\section{Pulper}

The pulper consists of a horizontal cylinder made of fine stainless steel. The heavy paddles inside the cylinder rotates rapidly, forcing the fine pulp to pass through the screen/sieves which is collected separately while the pieces of skin, seeds, fibre etc. pass out through another end of the machine. However, at home scale, the crushed tomatoes after heating can be strained manually through stainless steel sieves.

\section{Finishing and homogenization}

After extraction, edible common salt (0.4$0.6 \%$ ) and sugar $(1 \%)$ are added to the extracted pulp/juice to improve the taste and flavour of the finished product. For commercial production, the juice is homogenized for separation of liquid from the pulp and to impart a thick consistency and uniform appearance. For homogenization, the juice is heated to $66^{\circ} \mathrm{C}$ and forced under high pressure $(70 \mathrm{~kg} / \mathrm{cm} 2)$ to shear the particles and bring them to almost same size.

\section{Filling}

The finished juice is heated to $82-88^{\circ} \mathrm{C}$ and filled hot in pre-sterilized glass bottles as shown in Figure 4. The bottles are then hermetically sealed using crown corks and sterilized in boiling water $\left(100^{\circ} \mathrm{C}\right)$ for about $25-30$ minutes. Hot tomato juice $\left(82-88^{\circ} \mathrm{C}\right)$ can also be packed into plain or lacquered tin cans of appropriate size. The cans are then double seamed in a seamer and processed in boiling water for varying period of time depending upon the can size. Generally, the sterilization time at $100^{\circ} \mathrm{C}$ for different sizes of can is 25 minutes (A2 can), 30 minutes (A21/2 can) and 40 minutes (A10 can).

\section{Labeling and storage}

After sterilization, the cans are cooled and stored in a cool dry place. Glass bottles are allowed to air cool. Both bottles and cans are labeled before sending them to market/sale.

\section{FPO specifications}

According to FPO specifications, tomato juice shall be a liquid product derived from sound, fresh and fully ripe tomatoes practically free from insect and fungal attack or other blemishes affecting quality of the fruit and may contain finely divided insoluble solids from the flesh of tomatoes.

It shall be free from pieces of skin, seeds, bits of coarse tissue and extraneous matter.

The only substances that may be added are salt $(1.5 \% \mathrm{w} / \mathrm{w})$, sugar, dextrose, malic acid, ascorbic acid, citric acid and permitted colour.

The minimum total soluble solids free of salt shall be 5\% (w/w).

The finished product shall have good flavour characteristic of tomato and be free from burnt or any other objectionable flavour.

It shall be of good keeping quality and shall show no sign of fermentation when incubated at $37^{\circ} \mathrm{C}$ for 7 days. 
The mold count shall not exceed $30 \%$ of the field examined.

Harmful poisonous metals in tomato juice shall not be more than 1 ppm (lead) 100 ppm (copper on the dried tomato solids basis). 2 ppm (arsenic), $250 \mathrm{ppm}$ (tin) and $19 \mathrm{ppm}$ (zinc).

\section{Tomato puree}

Tomato puree is prepared from tomato pulp after evaporation/concentration of the juice or pulp to desired total soluble solids with or without addition of salt. According to FPO specification, tomato puree shall contain minimum of $9 \%$ total soluble solids excluding salt. The percentage of total soluble solids is required to be declared on the level of the product (Fig. 5).

\section{Method for preparation of tomato puree}

For preparation of puree the tomato pulp is prepared from ripe tomatoes either by hot pulping or by using cold pulping method as shown in Figure 8.

The pulp/juice is then concentrated either by using open cooking method in steam jacketed kettle or cooking by using vacuum pan. However, cooking under vacuum is desirable as the juice/pulp boils at much lower temperature $\left(71^{\circ} \mathrm{C}\right)$ which results in retention of original red colour and flavour with natural vitamin $\mathrm{C}$.

The pulp is concentrated to desired solids ( 9 to $12 \%$ solids), packaged in pre-sterilized bottles, crown corked and processed in boiling water for 25-30 minutes. Tomato puree can also be preserved by adding sodium benzoate ( 250 ppm benzoic acid). For packing in tin cans, the tomato puree is filled hot at $82-88^{\circ} \mathrm{C}$ and then the cans are closed and processed for 20 minutes at $100^{\circ} \mathrm{C}$.

\section{Tomato paste}

A concentrated tomato juice or pulp without skin and seeds and containing not less than $25 \%$ of tomato solids is known as tomato paste.

Depending on the degree of concentration, tomato paste can be further grouped into three groups:

Light tomato paste containing $25-29 \%$ of salt free tomatoes.

Medium tomato paste containing 29-33\% of salt free tomatoes.

Heavy tomato paste containing not less than $33 \%$ of salt free tomatoes.

\section{Method for preparation of tomato paste}

Method for preparation of tomato paste is shown in Figure 8. Tomato pulp or juice is concentrated to $14-15 \%$ soluble solids in open pans followed by concentration in vacuum pans and packing in pre-sterilized bottles while still hot.

In large scale processing units, the tomato paste is manufactured by using vacuum evaporators and packed either in tin can or in bulk aseptic packages. The tomato paste is utilized for manufacture of different products like ketchup, soup, sauce etc.

\section{FPO specification for tomato puree and paste}

According to FPO specifications, the tomato paste shall be derived from sound, fresh and fully ripe tomatoes practically free from insect or fungal attack or any other blemish affecting the quality of the fruit. Properly prepared and strained tomatoes shall be free from skin and seeds. 
The only substances that may be added are common salt, citric acid, ascorbic acid, spices, Permitted colour and preservatives.

The finished product shall have good flavour of the tomato and must be free from any other objectionable flavour.

It shall be of good keeping quality and shall show no sign of fermentation, when incubated at $37^{\circ} \mathrm{C}$ for seven days.

The mold count in the finished product shall not exceed $60 \%$ of the field examined.

The minimum percentage of soluble solids (w/w) free of salt in tomato paste and tomato puree should be $25 \%$ and $9 \%$ respectively.

\section{Tomato ketchup}

Tomato ketchup is the commercial product made either from fresh tomato by converting them into juice/pulp or by using tomato puree or tomato paste.

It is made by concentrating tomato juice or pulp without seeds and skin. Spices, salt, sugar, vinegar, onion, garlic etc. are added to the extent that the ketchup contains not less than $12 \%$ tomato solids and minimum of $25 \%$ total soluble solids (w/w). The juice or puree prepared earlier can be used for preparation of tomato ketchup. Generalized recipe for preparation of tomato ketchup is as under.

\section{Method for preparation of tomato ketchup}

The tomato juice is concentrated with spices, salt, sugar etc as shown in Figure 9. About 1/3 of the sugar is added initially at the time of commencing the boiling and the balance is added a little before the ketchup is ready. The sugar added initially helps to intensify and fix the red tomato colour. However if whole sugar is added initially with the pulp, it will require the boiling of pulp for longer duration, which will adversely affect the colour of the ketchup. Salt is added towards the end of boiling, as otherwise, it bleaches the tomato colour. Spices are placed in the muslin cloth and cloth is placed in boiling mixture. At the end cloth bag is pressed to squeeze the spices and cloth is taken out. Vinegar should be added when the ketchup has thickened sufficiently, so that the acid does not volatize away. Tomato ketchup generally contains $1.25-1.50 \%$ acid. The tomato ketchup is generally concentrated to $25-30 \%$ solids, out of which $12 \%$ solids are tomato solids. The ketchup is filled hot $\left(88^{\circ} \mathrm{C}\right)$ into pre-sterilized glass bottles, crown corked and processed for 30 minutes and cooled at room temperature (Fig. 6). Tomato ketchup may also contain benzoic acid as preservative.

\section{Tomato soup}

Tomato soup is a fairly popular product now a day. It can be prepared either from pulp or tomato juice. Butter or cream, spices, starch etc are used for preparation of soup. These are added in different proportions on the basis of desired taste. There are several recipes which give tomato soup a good quality.

\section{Method for preparation of tomato soup}

The juice is boiled in pans for concentration. Add spices in a cloth bag as in case of tomato ketchup, while it is being concentrated. In the mean while arrowroot and butter with small amount of juice are mixed to form smooth paste and added to the whole lot.

Boiling is continued to the desired consistency by stirring it continuously. At the end, sugar and salt are added and mixture is boiled for about 2 minutes to dissolve them. The soup is filled hot $\left(88^{\circ} \mathrm{C}\right)$ into cans and is processed at $100-110^{\circ} \mathrm{C}$ for $20-45$ minutes depending on the size of cans and cooled quickly after processing. 
Fig.1 Fresh tomatoes

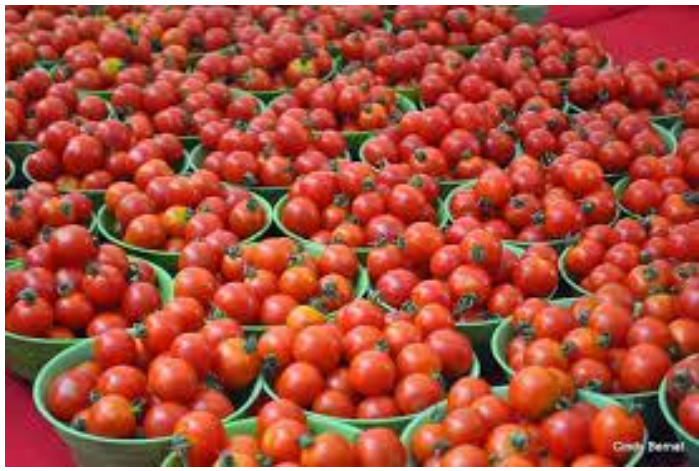

Fig.2 (a) Steam jacketed kettle with tomatoes, (b) Softened tomatoes ready for pulping, (c) tomato juice

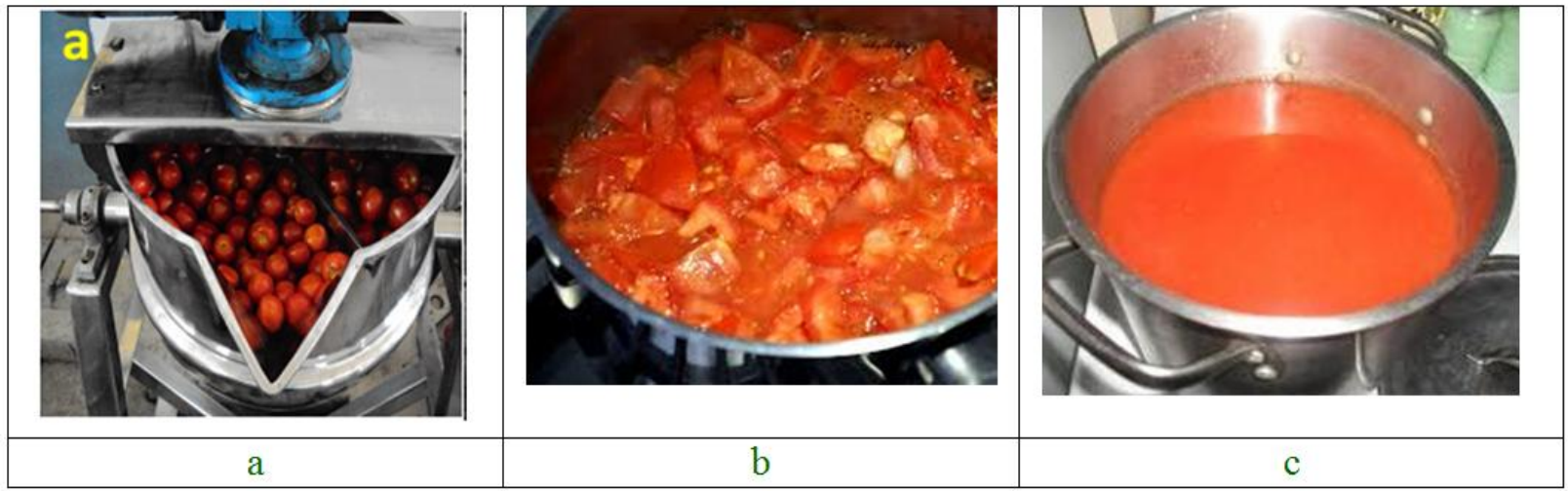

Fig.3 Hot pulping of tomato

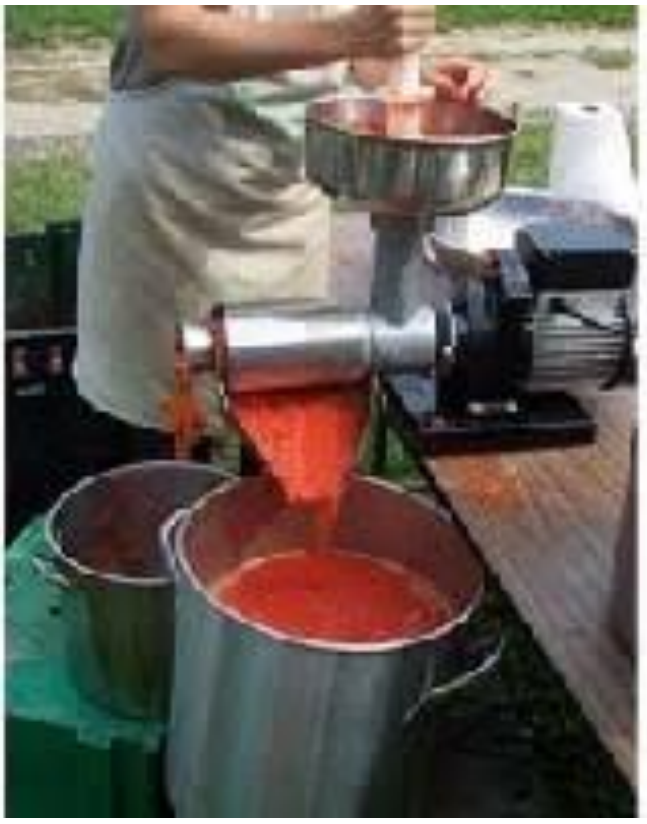


Fig.4 Crown corking of tomato juice

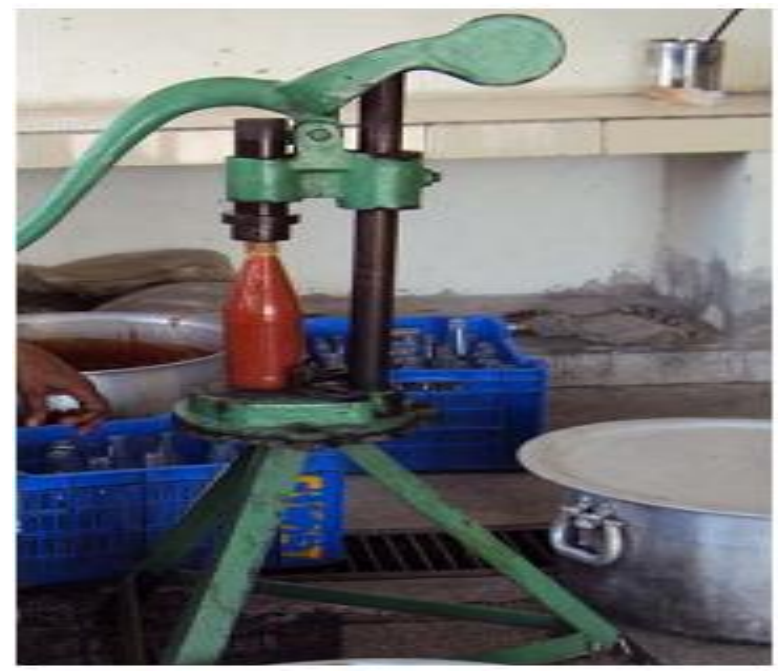

Fig.5 Tomato puree

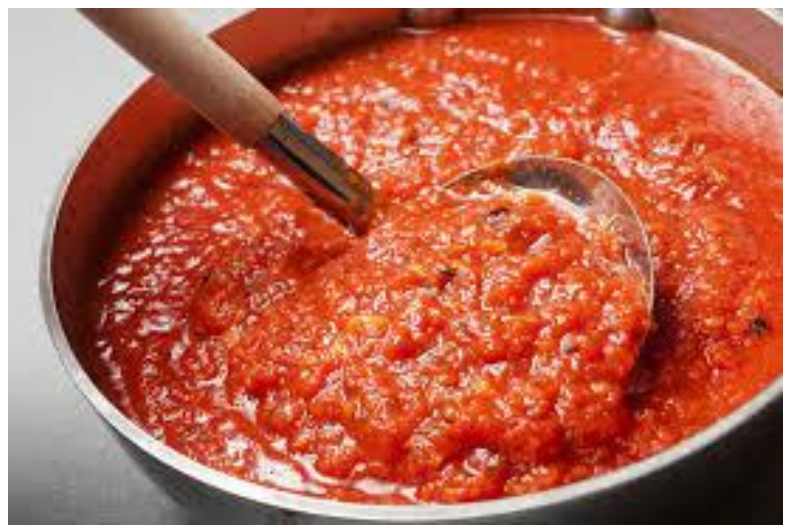

Recipe for ketchup

\begin{tabular}{|l|}
\multicolumn{1}{|c|}{ Ingredient } \\
\hline Tomato juice \\
\hline Onion (chopped) \\
\hline Garlic (Chopped) \\
\hline Red chillies powder \\
\hline Spices (Cloves, \\
cardamom, black \\
pepper, cinnamon) \\
\hline Glacial acetic acid \\
\hline Sugar \\
\hline Salt \\
\hline Benzoic acid \\
\hline
\end{tabular}

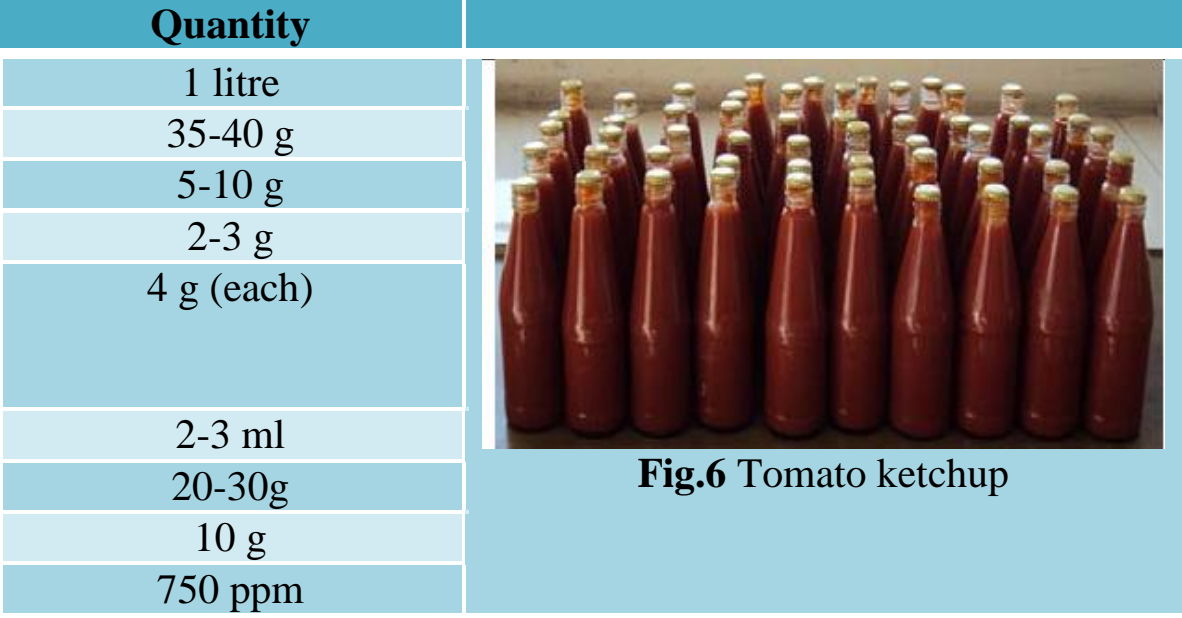




\section{Recipe for soup}

\begin{tabular}{|l|}
\hline Ingredient \\
\hline Tomato juice/pulp \\
\hline Salt \\
\hline Sugar \\
\hline Spices (Cardamom, black pepper, cinnamon, cumin) \\
\hline Onion (Chopped) \\
\hline Red chillies \\
\hline Cream or butter \\
\hline Arraroot starch \\
\hline Garlic (chopped) \\
\hline Water \\
\hline
\end{tabular}

\begin{tabular}{|c|}
\hline Quantity \\
\hline 1 litre \\
\hline $20 \mathrm{~g}$ \\
\hline $20 \mathrm{~g}$ \\
\hline $1 \mathrm{~g}($ each $)$ \\
\hline $20 \mathrm{~g}$ \\
\hline $2 \mathrm{~g}$ \\
\hline $20 \mathrm{~g}$ \\
\hline $10 \mathrm{~g}$ \\
\hline $5 \mathrm{~g}$ \\
\hline $350 \mathrm{ml}$
\end{tabular}

Fig.7 (a) Tomato pomace (byproduct) (b) Tray dried tomato pomace powder

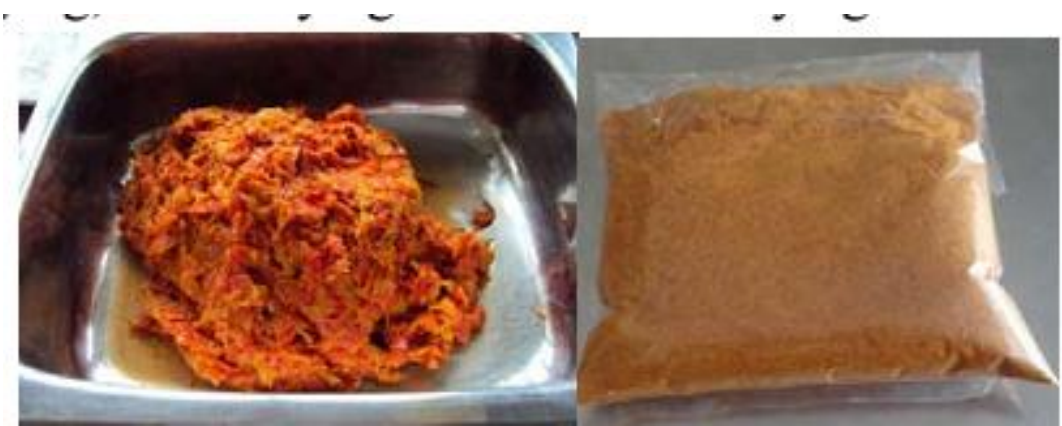

Fig.8 Flow sheet for preparation of tomato puree and pas

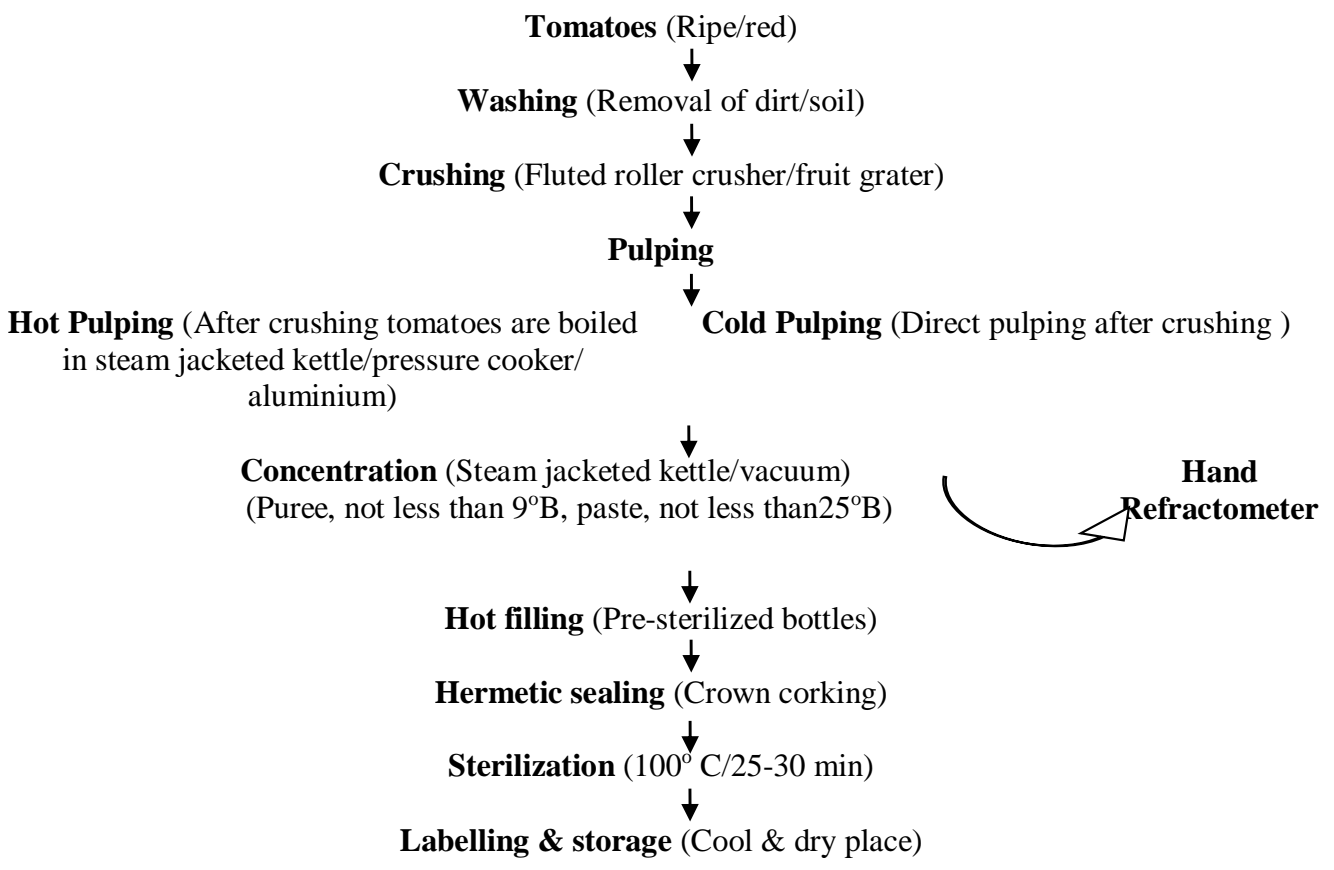


Fig.9 Flow sheet for preparation of tomato ketchup

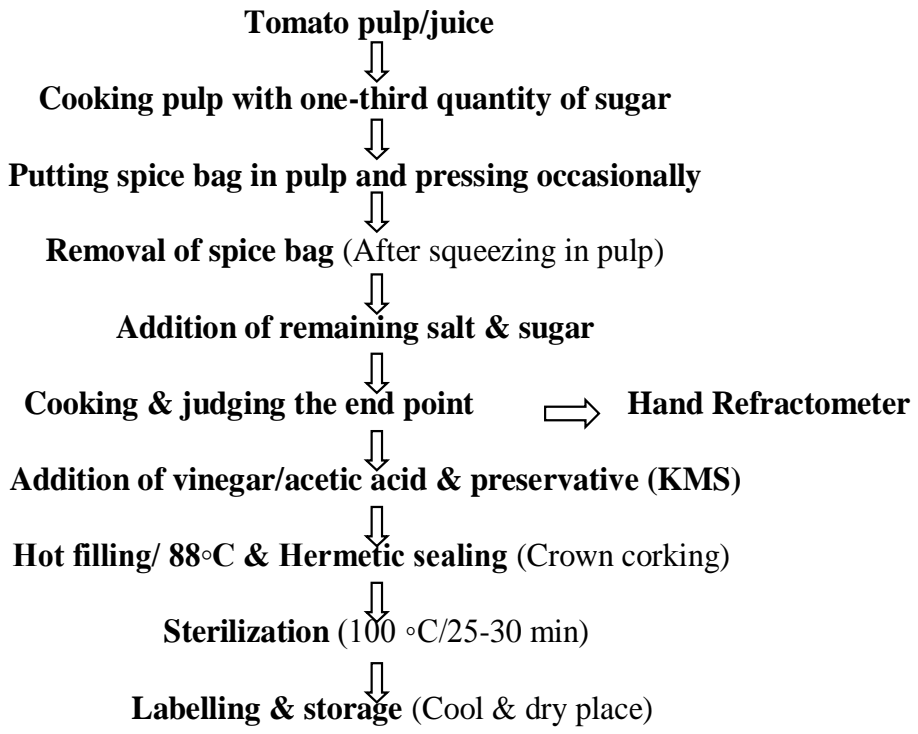

Table.1 Physical characteristics of tomato waste (Solid waste) on a dry weight basis (Barth and Powers, 2008; Hills and Nakano, 1984; Saev et al., 2009)

\begin{tabular}{|c|}
\hline Physical characteristics \\
\hline Moisture (\%) \\
\hline Ash (\%) \\
\hline Total solid (\%) \\
\hline Volatile solid (\%) \\
\hline
\end{tabular}

\section{Percentages $(\%)$ Values}

\begin{tabular}{|c|c|}
\hline $85-90$ \\
\hline $3.1-5.3$ \\
\hline $7-22.4$ \\
93.2 \\
\hline
\end{tabular}

Table.2 Chemical characteristics of tomato waste (Assi and King, 2008; Kavitha et al., 2005; Kramer and Kwee, 1977; Rizal et al., 2010)

\begin{tabular}{|c|}
\hline Chemical characteristics \\
\hline Starch $(\%)$ \\
\hline Cellulose $(\%)$ \\
\hline Hemicellulose $(\%)$ \\
\hline Protein/ amino acid $(\%)$ \\
\hline
\end{tabular}

Percentages $(\%)$ Values

\begin{tabular}{|c|}
\hline Percentages $(\%)$ Values \\
\hline $10-18$ \\
\hline $30-32$ \\
\hline $5-18$ \\
\hline $17-22$ \\
\hline
\end{tabular}

The different organisms involved in each stage are listed below in the table

\section{Stages involved}

Hydrolysis Acidogenesis

Methanogenesis

\section{Anaerobic Microorganism involved}

Facultative anaerobic bacteria including Cellulomonas, Eubacteria, Clostridium, Ruminococcus Facultative anaerobic acidogenic bacteria such as Escherichia coli, Clostridium, Actinomyces, Corynebacterium

Methanogens i.e. Methane producing anaerobic bacteria like Methanobacterium, Methanococcus, Methanosarcina 


\section{Tomato powder}

Pomace left after juice extraction and pulping is converted into powder by tray drying, drum drying or freeze drying. The quality of powder obtained is excellent with freeze and drum drying but the quality with tray drying is not up to the mark. However, farmers or entrepreneurs with basic facilities can convert left out pomace or processed byproduct into tomato powder. The developed tomato powder can be used for fortification in tomato soup preparations, ketchup manufacture or even while cooking dishes involving rice. Commercially, tomato juice is converted into a free flowing, highly hygroscopic powder by using different drying methods. Sometimes the natural tomato flavour in powder form is incorporated to compensate any loss of flavour to yield full strength juice powder. Juice can be converted to powder by using different methods like spray drying, roller drying and foam mat drying (Fig. 7).

\section{Value addition of tomato waste/tomato processing waste through microbial processing}

\section{Tomato/vegetable waste}

Tomato and other vegetable waste is a biodegradable material generated in large quantities, much of which is dumped on land to rot in the open, which not only emits a foul odour, but also creates a big nuisance by attracting birds, rats, and pigs-vectors of various diseases. Apart from post-harvest losses due to lack of storage capacity, processing and packaging of vegetables according to customers' specifications also plays a major role in waste generation.

\section{Tomato waste: physical and chemical characteristics}

Tomato as well other vegetable waste is generally characterized for various physical, chemical, or biological properties. Physical characterization of tomato wastes include estimation of weight, volume, moisture, ash, total solid, volatile solid (VS), colour, odour, temperature, etc., while Chemical studies include the measurement of cellulose, hemicellulose, starch, reducing sugars, protein, total organic carbon, phosphorus, nitrogen, $\mathrm{BOD}, \mathrm{COD}, \mathrm{pH}$, halogens, toxic metals, etc.. Physical and chemical characteristics of tomato waste have been given in table 1 and 2.

\section{Tomato waste utilization: Role of microorganisms}

Biodegradable nature of tomato/vegetable wastes makes the component easily accessible to microorganisms and provides a viable solution to detrimental environmental effects. Microbes are potential candidate for reprocessing and eventual utilization of vegetable processing residues. Tomatoes are one of the wasted vegetables prominently investigated and exploited for biogas production. These wastes can be used as raw material/substrate for the growth of various microbes which in turn used for biofuel (Biomethane, bio hydrogen, bioethanol and biobutanol) production through fermentation under controlled conditions or else used for composting. The natural decomposition of wastes by microbes generates products with high humus content which is natural soil fertility enhancer. Besides this, tomato waste can be used for the production microbial biomass, polysaccharides/polymer or/and single cell proteins.

\section{Production of biomethane/biogas: source of renewable energy}

Biomethane, obtained during anaerobic digestion by the microbial community, is a cheap form of renewable energy that is 
environmentally friendly. Normally, biogas is composed of 45-70\% methane, 30-45\% carbon dioxide, $0.5-1.0 \%$ hydrogen sulphide, 1-5\% water vapour, and a small amount of other gases (hydrogen, ammonia, nitrogen, etc.). Biomethane production is a three step process involving hydrolysis, acidogenesis, and methanogenesis which is accomplished by a series of microbial interactions. Use of tomato waste for biogas production not only solves the problem of residual disposal and indoor pollution, but also reduces dependency on fuel wood. The process of biogas production involves three stages.

Tomato waste as raw substrate for single cell protein

Single cell proteins are cell or whole microorganism used as source of protein for human, animal feed or supplements. Several vegetable wastes including tomato waste are used as raw materials for the single cell protein (SCP) production (Viswanath, 1992). Compared to conventional methods, microbial production of SCP has several advantages such as high protein content and short growth times leading to rapid biomass production, which can be continuous and is independent of the environmental conditions (Bekatorou et al., 2006). Numerous microbial groups such as filamentous fungi (Aspergillus, Fusarium, Rhizopus, etc.), Alga (Spirullina, Chlorella etc.) and many bacterial species (Bacillus, Lactobacillus, Pseudomonas etc.) are extensively used in SCP production (Bhalla $e t$ al., 1999).

Tomato waste as raw substrate for production other valuable microbe based products microbial biopolymer, biomass enzymes and numerous valuable metabolites

Tomato waste can be used as raw material for the production of microbial biomass
(Biofertilizers, Biopesticides), microbial endo and exopolymers (For e.g. Polyhydroxybutyric acid (PHB) production) which finds application in food packaging, medicine and agriculture industry, polysaccharides from vegetable/tomato waste and production various microbial extracellular industrial important enzymes (amylase, cellulase etc.) with use of fermentation technology. Some selected extremophilic bacteria have shown enhanced production of microbial biomass, enzymes and biopolymers when grown on tomato and other vegetable waste (Donato et al., 2014).

Tomato waste to compost: as organic fertilizer and soil conditioner

The solid, fibrous component (referred as compost) of the anaerobically digested material of tomato waste can be used as a soil conditioner to increase the organic content of soils. Organic compost prepared from tomato/vegetable waste can be used as a fertilizer to supply vital nutrients to soils instead of chemical fertilizers that require large amounts of energy to produce and transport.

\section{References}

Andries S., Filipiuc V., 2014- Eficacitatea irigatiei in conditiile RM. In: Akademos, Chisinau, nr. 3 (34), p.101.

Cimpoes D., Golban A., 2013- The competitiveness of high value added agriculture and major factors of its increasing: the case of the Republic of Moldova. In: Scientific papers series. Management, economic engineering in agriculture and rural development,' Volume 13 Issue 2/2013. Bucuresti: USAMVB, p. 41-47.

Dunlap A (2006). Checklist for starting value added agriculture enterprise. The valueadded and alternative agriculture start- 
up tool kit. The NC state university cooperative extension. http://www.irs. org/business

Kotler P., Pfoertsch W., 2006 -B2B Brand Management. Springer -Verlag Berlin Heidelberg, 2006, 357 p.
White P., Cipciriuc L., Belschi A., 2011Studiu de piata privind fructele si legumele proaspete in Moldova. Chisinau: USAID/ACED.

\section{How to cite this article:}

Archana Kumari and Jitendra Singh. 2018. Physical and Chemical Evaluation of Tomato and Its Value Addition. Int.J.Curr.Microbiol.App.Sci. 7(04): 2851-2862.

doi: https://doi.org/10.20546/ijcmas.2018.704.325 